\title{
Overcoming a travel burden to high- volume centers for treatment of retroperitoneal sarcomas is associated with improved survival
}

\author{
Robin Schmitz ${ }^{*}$, Mohamed A. Adam and Dan G. Blazer III
}

\begin{abstract}
Background: Guidelines recommend treatment of retroperitoneal sarcomas (RPS) at high-volume centers. However, high-volume centers may not be accessible locally. This national study compared outcomes of RPS resection between local low-volume centers and more distant high-volume centers.

Methods: Patients treated for RPS were identified from the National Cancer Database (1998-2012). Travel distance and annual hospital volume were divided into quartiles. Two groups were identified: (1) short travel to low-volume hospitals (ST/LV), (2) long travel to high-volume hospitals (LT/HV). Outcomes were adjusted for clinical, tumor, and treatment characteristics.

Results: Two thousand five hundred ninety-nine patients met the inclusion criteria. The LT/HV cohort was younger and more often white $(p<0.01)$. The LT/HV group had more comorbidities, higher tumor grade, and more often radical resections and radiotherapy (all $p<0.05)$. The ST/LV group underwent significantly more R2 resections $(4.4 \%$ vs. $2.6 \%, p=0.003)$. Thirty-day mortality was significantly lower in the LT/HV group ( $1.2 \%$ vs. $2.8 \%, p=0.0026)$. Fiveyear survival was better among the LT/HV group (63\% vs. 53\%, $p<0.0001)$. After adjustment, the LT/HV group had a $27 \%$ improvement in overall survival (HR 0.73, $p=0.0009$ ).

Conclusions: This national study suggests that traveling to high-volume centers for the treatment of RPS confers a significant short-term and long-term survival advantage, supporting centralized care for RPS.
\end{abstract}

Keywords: RPS, Travel distance, Volume outcomes, Survival

\section{Introduction}

Soft tissue sarcomas (STS) are a heterogeneous group of tumors that include more than 100 different entities as described in the World Health Organization classification from 2013 [1]. The estimated incidence of STS is approximately 12,750 new cases in the USA in 2019, with an estimated 5270 deaths [2]. Approximately, 15\% of all soft tissue sarcomas arise from the retroperitoneum, and this primary site is one of the most difficult areas to treat, given the proximity to major vascular structures and other organs $[3,4]$.

\footnotetext{
* Correspondence: robin.schmitz@duke.edu

Department of Surgery, Duke University Medical Center, Durham, NC, USA
}

The primary treatment modality for localized retroperitoneal sarcoma (RPS) is surgical resection. Accomplishing complete resection with grossly negative margins is crucial and associated with improved longterm survival $[5,6]$. In fact, postoperative margin status is one of the strongest predictors of outcome in these patients, with median survival differences as large as 103 vs. 18 months based on gross margin status [6]. Despite best efforts, recurrence rates in these patients can be as high as $50-70 \%$. In an effort to decrease recurrence, various strategies have been employed, including extended resection techniques and perioperative radiation therapy, with promising outcomes [7-9].

Given the surgical complexity and the potential role of multimodal treatment strategies to improve outcomes, 
evaluation of these patients at high-volume centers with multidisciplinary evaluation is recommended [10]. Recent analyses of the NCDB revealed a higher short- and longterm mortality as well as lower R0 resection rate and higher local recurrence rate in patients treated at lowvolume centers [11-13]. Population-based studies from Europe similarly revealed higher local recurrence rates in patients not treated at specialized centers $[14,15]$. However, not every patient has the ability to pursue care at high-volume, specialized centers, especially when a long travel distance is associated with specialized care.

The relationship between patients' travel burden to specialized care and their outcomes is not well described in the literature and unanswered for RPS. Some studies have shown that long travel to high-volume medical centers is associated with improved patient outcomes [16, 17]. Yet, some patients prefer to be treated locally. Arguments for treatment at local, low-volume institutions include the reduced travel time for patients and their families, familiarity with the facilities and providers, and the immediate presence of their local support system.

Given the complexity of the treatment of retroperitoneal sarcomas, we hypothesized that traveling long distance for treatment at high-volume institutions would be associated with improved patient outcomes versus short travel distance to a low-volume center. We used the National Cancer Database (NCDB), a robust national database that includes $70 \%$ of all cancer cases in this country, to address this question [18].

\section{Materials and methods}

\section{Data source and study design}

This retrospective analysis from the NCDB was approved by the Duke University Institutional Review Board. Patients who underwent resection of a retroperitoneal sarcoma between 1998 and 2012 were identified by the International Classification of Disease for Oncology, 3rd Edition (ICD-O-3) topography codes: 8800, 8801, 8802, 8810, 8830, 8850, 8851, 8852, 8853, 8854, 8858, 8890, 9120, 9540. We excluded patients with missing travel distance or extent of surgery data. Travel distance in the NCDB is calculated as the distance between the center of the patient's residential zip code and the address of the treating hospital, using Haversine's formula [19]. Annual hospital volume was calculated for each hospital as the number of RP cases performed at a hospital per year. Patients treated at multiple hospitals were excluded.

All study endpoints were determined prior to data analysis. Preoperative endpoints included neoadjuvant therapy. Perioperative endpoints included surgical margins, hospital length of stay (LOS), 30-day readmission rate, and 30-day mortality. Long-term postoperative endpoints included administration of adjuvant radiotherapy and overall survival calculated as the time from surgery to death or last contact.

\section{Statistical analysis}

Travel distance to treatment centers and annual hospital volume were divided into quartiles. Overlaying the upper and lower quartiles of travel distance with hospital volume, we identify two groups: (1) short patient travel to low-volume hospitals (ST/LV), (2) long patient travel to high-volume hospitals (LT/HV). The above-described outcomes were compared using the Wilcoxon rank-sum test for continuous variables and chi-square or Fisher exact tests for categorical variables. Multivariable logistic regression and Cox proportional hazards models were employed to examine the association between travel distance and the endpoints while adjusting for clinical, tumor, and treatment characteristics, including patient age, gender, race, insurance status, comorbidities, tumor grade, extent of surgery, and radiation therapy.

A two-sided significance level of $<0.05$ was used for all statistical tests. All statistical analyses were performed using SAS 9.4 (SAS Institute, Cary, NC).

\section{Results}

A total of 2599 patients with retroperitoneal sarcoma were identified in the NCDB between 1998 and 2012 who met inclusion criteria (Fig. 1). Patient characteristics are summarized in Table 1. The median patient age was 61 with a similar gender distribution $(51.9 \%$ vs. $48.1 \%)$. The median travel distance was 14 miles and the median annual hospital RPS case volume was 3 cases/year.

One thousand three hundred nine patients were classified as ST/LV group who traveled a median of 4 miles to local medical centers with a median annual case volume of 1 case/year. The second cohort summarized as LT/ HV included 1250 patients who traveled a median distance of 56 miles to pursue treatment at high-volume institutions with a median annual case volume of 10 cases/ year.

Patients in the LT/HV group were significantly younger and more frequently white $(p<0.05)$. There was no significant difference in the patients' income and insurance status between the two groups.

In regard to disease-specific characteristics, LT/HV patients had significantly more high-grade sarcomas $(p=0.024)$. Furthermore, patients in the LT/HV cohort underwent more frequent radical resections, defined as resection of other organs in continuity to the primary tumor $(51.1 \%$ vs. $28.4 \%)$, and received more perioperative radiotherapy (all $p<0.05$ ). ST/LV patients had significantly more $\mathrm{R} 2$ resections $(4.4 \%$ vs. $2.6 \%, p=0.003$, Table 2).

No significant difference was identified between groups in the 30-day unplanned readmission rate. Thirty-day 


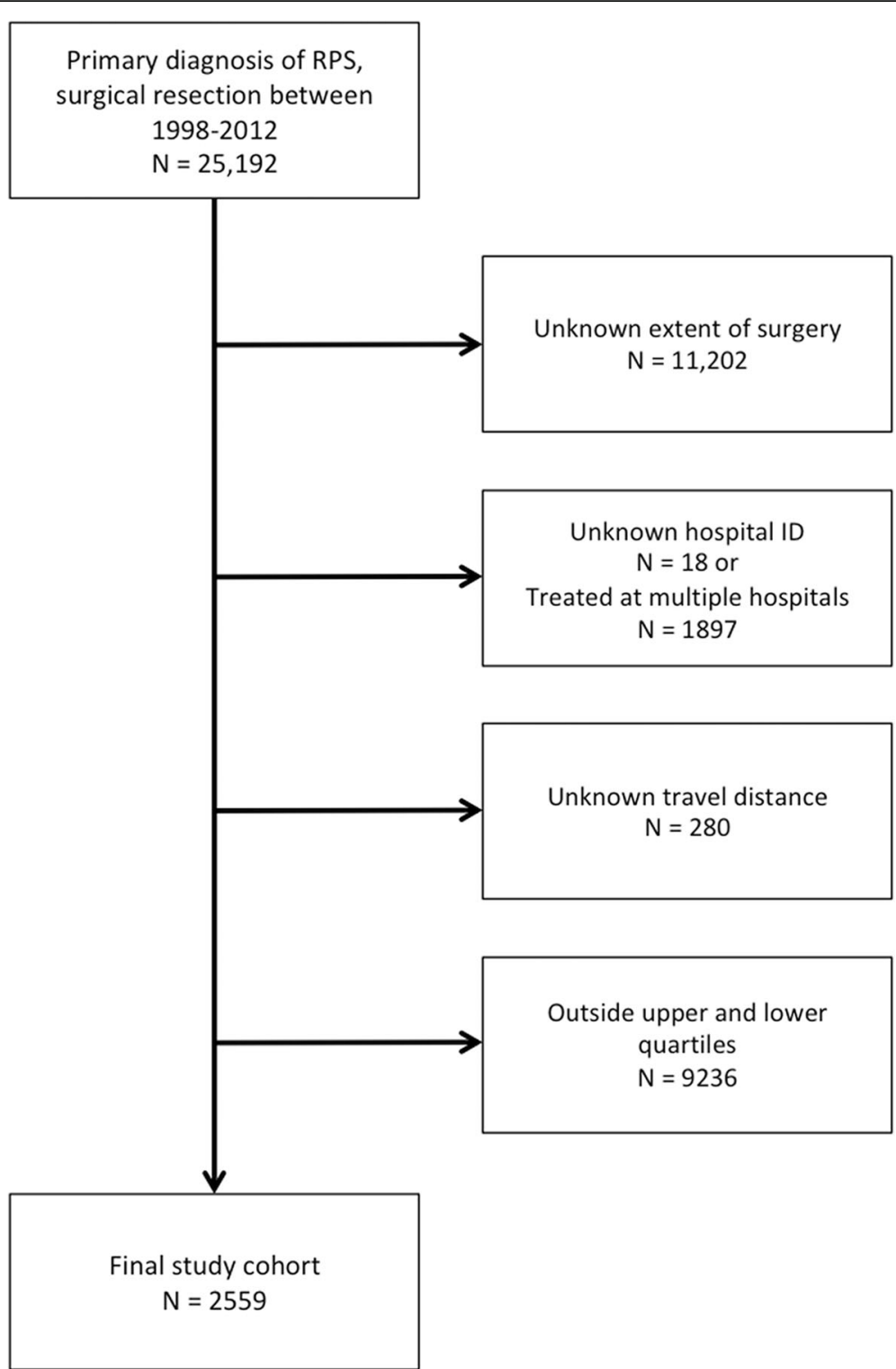

Fig. 1 Patient selection and inclusion/exclusion criteria

mortality was significantly lower in the LT/HV group $(1.2 \%$ vs. $2.8 \%, p=0.0026)$. Five-year survival was better in the LT/HV group (63\% vs. $53 \%, p<0.0001$ ) (Fig. 2), with a median follow-up of 33 months. After adjustment for patient- and disease-specific differences, the LT/HV group had a $27 \%$ survival benefit (HR 0.73, $p=0.0009$ ) (Table 3).

\section{Discussion}

In this nationwide analysis of the NCDB, we investigated the impact of travel distance and hospital case volume on the short- and long-term outcomes of patients with retroperitoneal sarcoma. Given the oftentimes complex and challenging multidisciplinary treatment of RPS, we hypothesized that it remains beneficial for patients to overcome a travel burden to receive care at high-volume centers. This study demonstrates improved short- and long-term outcomes for patients traveling longer distance to high-volume centers. Both 30-day mortality and long-term survival were significantly improved in the group of patients who traveled long distance to highvolume centers versus those patients who stayed closer to home and received care at lower-volume centers. Additionally, patients who traveled short distance to low-volume centers had a significantly higher rate of oncologically inferior $\mathrm{R} 2$ resections.

The relationship between hospital volume and improved outcomes is well described in the literature [20-23]. Birkmeyer et al. summarized Medicare data 
Table 1 Characteristics of all included patients from the National Cancer Database who underwent treatment for retroperitoneal sarcomas

\begin{tabular}{|c|c|}
\hline & Overall cohort $(N=2599)$ \\
\hline Age (years, median, IQR) & $61(51-72)$ \\
\hline \multicolumn{2}{|l|}{ Gender } \\
\hline Female & $1328(51.9 \%)$ \\
\hline Male & $1231(48.1 \%)$ \\
\hline \multicolumn{2}{|l|}{ Race } \\
\hline Black & $233(9.1 \%)$ \\
\hline Other & $122(4.8 \%)$ \\
\hline White & $2204(86.1 \%)$ \\
\hline \multicolumn{2}{|l|}{ Income } \\
\hline Below median & $733(28.6 \%)$ \\
\hline Above median & $1763(68.9 \%)$ \\
\hline \multicolumn{2}{|l|}{ Insurance status } \\
\hline None & $69(2.7 \%)$ \\
\hline Private/government & $2300(89.9 \%)$ \\
\hline Annual hospital volume (cases, median, IQR) & $3(1-10)$ \\
\hline Travel distance (miles, median, IQR) & $14(4-63)$ \\
\hline \multicolumn{2}{|l|}{ Charlson-Deyo score } \\
\hline 0 & $1475(57.6 \%)$ \\
\hline 1 & $319(12.5 \%)$ \\
\hline$\geq 2$ & $77(3.0 \%)$ \\
\hline \multicolumn{2}{|l|}{ Tumor grade } \\
\hline 1 & $742(29 \%)$ \\
\hline 2 & $318(12.4 \%)$ \\
\hline 3 & $1057(41.3 \%)$ \\
\hline Neoadjuvant therapy & $73(2.9 \%)$ \\
\hline \multicolumn{2}{|l|}{ Extent of surgery } \\
\hline Local & $757(29.6 \%)$ \\
\hline Radical & $1011(39.5 \%)$ \\
\hline Simple & 791 (30.9\%) \\
\hline \multicolumn{2}{|l|}{ Appropriateness of resection } \\
\hline R2 & $89(3.5 \%)$ \\
\hline $\mathrm{R} 0 / 1$ & $1722(67.3 \%)$ \\
\hline Hospital length of stay (days, median, IQR) & $6(3-8)$ \\
\hline Radiotherapy & $689(26.9 \%)$ \\
\hline 30-day mortality & $95(3.7 \%)$ \\
\hline 30-day readmission & $95(3.7 \%)$ \\
\hline
\end{tabular}

in 2002 that included a total of 2.5 million cases in cardiovascular and cancer surgery. Absolute differences in adjusted mortality rates between low-volume and high-volume centers were as high as $12 \%$ for pancreatic resections and as low as $0.2 \%$ for carotid endarterectomies [24]. The same group went on to demonstrate improved mortality rates as hospital volumes rose over time [25]. Despite increased awareness and improvements in hospital safety over time, this relationship between higher volume hospitals and improved mortality has remained strong [20-23, 26].

Similar results have also been demonstrated for retroperitoneal sarcomas. In an analysis of the NCDB including more than 5000 patients between 2004 and 2013, patients were divided in 3 groups depending on annual hospital case volume: low volume $(<5$ cases/year), medium volume (5-10 cases/year), and high volume (> 
Table 2 Unadjusted characteristics of patients who underwent surgical treatment of retroperitoneal sarcomas at local, low-volume centers (ST/LV) and patients traveling long distance to high-volume centers (LT/HV)

\begin{tabular}{|c|c|c|c|}
\hline & LT/HV $(N=1250)$ & ST/LV $(N=1309)$ & $p$ value \\
\hline Patient age (years, median, IQR) & $59(50-69)$ & $64(52-75)$ & $<0.0001$ \\
\hline Gender & & & 0.011 \\
\hline Female & $681(54.5 \%)$ & $647(49.4 \%)$ & \\
\hline Male & $569(45.5 \%)$ & $662(50.6 \%)$ & \\
\hline Race & & & 0.009 \\
\hline Black & $92(7.4 \%)$ & $141(10.8 \%)$ & \\
\hline Other & $64(5.1 \%)$ & $58(4.4 \%)$ & \\
\hline White & $1094(87.5 \%)$ & $1110(84.8 \%)$ & \\
\hline Income & & & 0.071 \\
\hline Below median & $375(30 \%)$ & $358(27.4 \%)$ & \\
\hline Above median & $832(66.6 \%)$ & $931(71.1 \%)$ & \\
\hline Insurance status & & & 0.393 \\
\hline None & $28(2.2 \%)$ & $41(3.1 \%)$ & \\
\hline Private/government & $1057(84.6 \%)$ & 1243 (95\%) & \\
\hline Annual hospital volume (cases, median, IQR) & $10(7-14)$ & $1(1-2)$ & $<0.0001$ \\
\hline Travel distance (miles, median, IQR) & $56(19-132)$ & $4(2-11)$ & $<0.0001$ \\
\hline Charlson-Deyo score & & & 0.017 \\
\hline 0 & $940(75.2 \%)$ & $535(40.9 \%)$ & \\
\hline 1 & $192(15.4 \%)$ & $127(9.7 \%)$ & \\
\hline$\geq 2$ & $39(3.1 \%)$ & $38(2.9 \%)$ & \\
\hline Tumor grade & & & 0.024 \\
\hline 1 & $368(29.4 \%)$ & $374(28.6 \%)$ & \\
\hline 2 & $146(11.7 \%)$ & $172(13.1 \%)$ & \\
\hline 3 & $570(45.6 \%)$ & $487(37.2 \%)$ & \\
\hline Neoadjuvant therapy & $61(4.9 \%)$ & $12(0.9 \%)$ & $<0.0001$ \\
\hline Extent of surgery & & & $<0.0001$ \\
\hline Local & $193(15.4 \%)$ & $564(43.1 \%)$ & \\
\hline Radical & $639(51.1 \%)$ & $372(28.4 \%)$ & \\
\hline Simple & $418(33.4 \%)$ & $373(28.5 \%)$ & \\
\hline Appropriateness of resection & & & 0.003 \\
\hline R2 & $32(2.6 \%)$ & $57(4.4 \%)$ & \\
\hline $\mathrm{R} 0 / 1$ & $894(71.5 \%)$ & $828(63.3 \%)$ & \\
\hline Hospital length of stay (days, median, IQR) & $6(4-9)$ & $5(1-7)$ & $<0.0001$ \\
\hline Radiotherapy & $362(29 \%)$ & $327(25)$ & 0.044 \\
\hline 30-day mortality & $15(1.2 \%)$ & $36(2.8 \%)$ & 0.0026 \\
\hline 30-day readmission & $56(4.5 \%)$ & 39 (3.0\%) & 0.38 \\
\hline
\end{tabular}

10 cases/year). Patients treated at low-volume institutions had a significantly higher risk of 30-day mortality (adjusted OR $=4.66,95 \%$ CI 2.26-9.63) and long-term mortality (adjusted HR $=1.56,95 \%$ CI $1.16-2.11$ ) compared to high-volume institutions [11]. Another study of the NCDB revealed that patients treated at high-volume centers had 2.5-fold higher odds of receiving a R0/R1 resection $(p=0.026)$, and 1.8 -fold higher odds of an R0 resection $(P<0.001)$. High volume was defined as the upper 10th percentile in this study [27]. As outlined above, high- and low-volume centers are not clearly defined in the literature, though a few studies have used 10 cases per year as a cut-off $[11,13]$. Our group previously failed to define a clear cut off [28]. Thus, in this analysis, we divided the cohort into quartiles to maintain objectivity. 


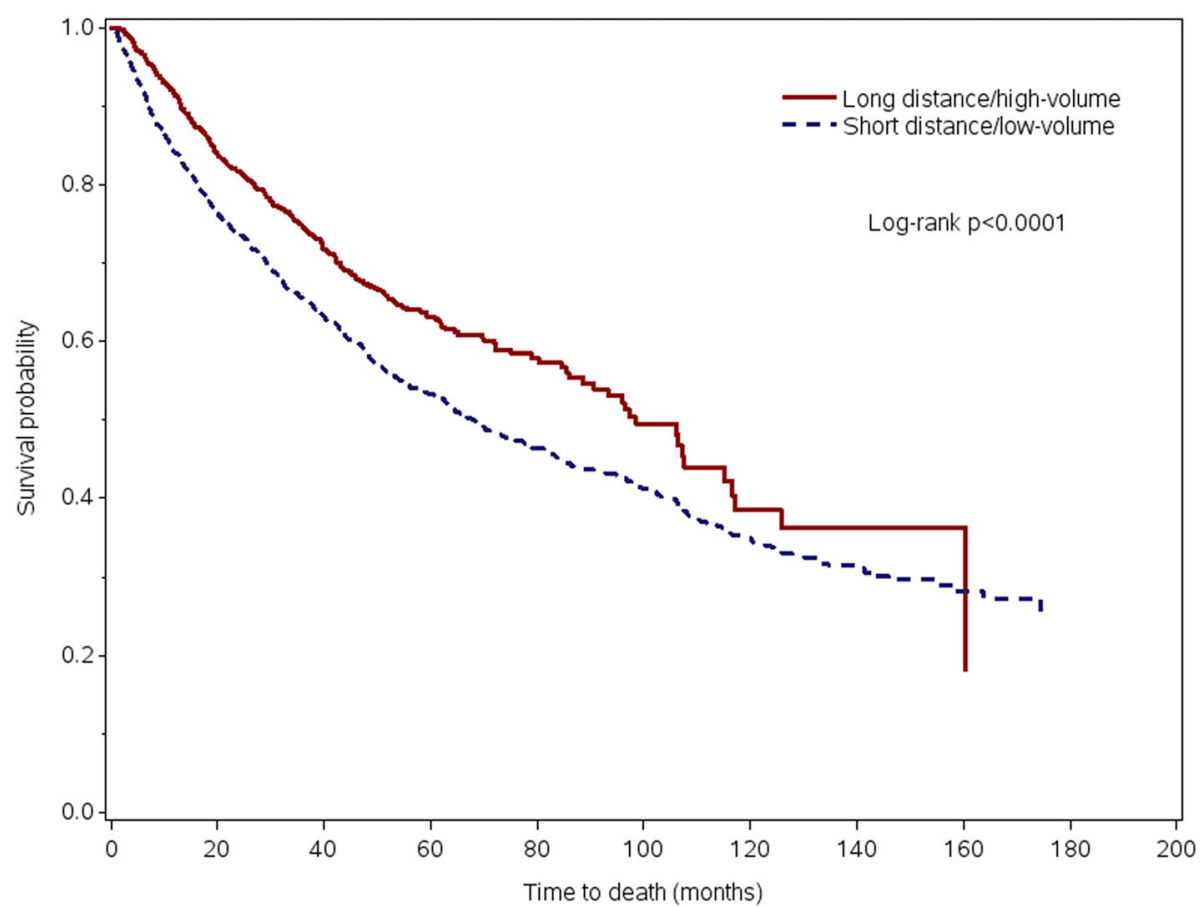

Fig. 2 Unadjusted overall survival for patients who traveled to high-volume centers vs. those receiving surgical care at local low-volume centers

Clearly, the definition of a sarcoma center of excellence goes beyond surgical volume alone. A population-based study from Sweden with 375 patients revealed higher local recurrence rates in patients not treated at a specialized center [14]. A similar study from Great Britain confirmed these results with a significantly higher local recurrence rate at local hospitals (39\% vs. 19\%) and a small overall survival benefit [15]. A recent analysis of the NCDB showed that resection for RPS performed at academic cancer centers was an independent predictor of margin-negative resection [12]. Finally, in a very compelling analysis from the NETSARC and French Sarcoma Group, investigators demonstrated that patients undergoing surgery in a network of 26 sarcoma reference centers (defined by a multidisciplinary tumor board and expert pathology review) demonstrated improved overall and relapse-free survival rates [29].

Table 3 Adjusted overall survival for patients who traveled to high-volume centers vs. patients who received low-volume surgical care locally

\begin{tabular}{|c|c|c|c|c|}
\hline & Hazard ratio & Lower 95\% Cl & Upper 95\% Cl & $p$ value \\
\hline $\mathrm{LT} / \mathrm{HV} V^{\mathrm{a}}$ travel & 0.726 & 0.601 & 0.878 & 0.0009 \\
\hline Patient age (years, median, IQR) & 1.024 & 1.017 & 1.031 & $<0.0001$ \\
\hline Female gender & 0.971 & 0.807 & 1.168 & 0.752 \\
\hline \multicolumn{5}{|l|}{ Race } \\
\hline Black & 1.030 & 0.745 & 1.426 & 0.857 \\
\hline Other & 0.867 & 0.552 & 1.362 & 0.535 \\
\hline Insurance status & 0.673 & 0.356 & 1.273 & 0.223 \\
\hline \multicolumn{5}{|l|}{ Charlson-Deyo score } \\
\hline 1 & 1.374 & 1.100 & 1.717 & 0.0052 \\
\hline 2 & 1.328 & 0.885 & 1.993 & 0.171 \\
\hline \multicolumn{5}{|l|}{ Tumor grade } \\
\hline 2 & 1.720 & 1.202 & 2.460 & 0.003 \\
\hline 3 & 3.910 & 3.049 & 5.015 & $<0.0001$ \\
\hline Radiotherapy & 0.754 & 0.615 & 0.925 & 0.0068 \\
\hline
\end{tabular}

${ }^{a}$ Long distance travel to high-volume centers 
Despite compelling data demonstrating improved outcomes at more experienced sarcoma centers, patients still choose to pursue care locally. In a novel analysis by Finlayson et al. evaluating patient preferences surrounding pancreatectomy, $45 \%$ of patients were willing to accept double the operative mortality risk in order to stay locally [30]. In addition, numerous hypothetical advantages may accrue to patients who receive treatment locally: reduced travel time for patients and their families, familiarity with the facilities and providers, and the immediate presence of their local support system [30]. These advantages may be particularly important in postoperative care if close follow-up or readmission is needed. In addition, neoadjuvant or adjuvant therapy, as may be recommended for some patients with retroperitoneal sarcoma, may only be feasible for patients locally, due to financial and social support reasons. However, in fact, our analysis demonstrates that patients in the ST/ LV group were less likely to receive perioperative radiotherapy. Though it is possible that radiotherapy was given locally and underreported to the NCDB, similar results have been observed for pancreatic cancer and colon cancer, where patients received significantly less frequent adjuvant therapy at low-volume centers $[17,31]$.

Despite these hypothetical advantages of pursuing treatment closer to home, our data strongly support travel to higher-volume centers for the management of resectable RPS. Short-term operative mortality was improved despite more radical resections. Decreased rates of R2 resections were accomplished in high-volume centers. These outcomes likely reflect greater surgeon experience with these rare, complex malignancies, better perioperative care for these patients, and availability of other subspecialty expertise. Longer-term oncologic outcomes were also improved despite higher-grade tumors in the LT/HV group (HR 0.73, $p=0.0009$ ). These findings may be attributed to decreased $\mathrm{R} 2$ resection rates but may also reflect better multidisciplinary care, including consideration of perioperative radiation therapy, closer oncologic surveillance, and consideration of novel clinical trials.

From the NCDB, we are unable to reliably explore what level of information is available to patients considering resection for RPS (tumor board discussion, surgical volume, multidisciplinary expertise in soft tissue sarcoma). In the future, these data will likely inform hospital-level accreditation and should inform patient decision-making more strongly.

This analysis has limitations. It is a retrospective analysis of a large dataset. Important data are missing, including locoregional and distant recurrence data. However, the NCDB is a well-validated dataset that captures more than $70 \%$ of newly diagnosed cancer cases in the USA.

\section{Conclusion}

This study demonstrates the advantages and importance of patients pursuing care at high-volume institutions, regardless of travel distance involved. We demonstrate both improved short- and long-term outcomes, likely reflecting both improved perioperative morbidity and superior oncologic outcomes. It is crucial that referring providers educate their patients about these data when giving recommendations about where to pursue care.

\section{Acknowledgements}

Not applicable

\section{Authors' contributions}

RS interpreted the patient data and was a major contributor in writing the manuscript. MAA performed all statistical analyses of the reported data. MAA also contributed to data interpretation and revised the manuscript. DGB contributed significantly to data interpretation and discussion of the results. DGB also revised the manuscript prior to submission. All authors read and approved the final manuscript.

\section{Funding}

The authors received no funding for this study.

\section{Availability of data and materials}

The datasets used and/or analyzed during the current study are available from the corresponding author on reasonable request.

\section{Ethics approval and consent to participate}

This retrospective analysis from the NCDB was approved by the Duke University Institutional Review Board.

\section{Consent for publication}

Not applicable

\section{Competing interests}

The authors declare that they have no competing interests.

Received: 28 July 2019 Accepted: 15 October 2019

Published online: 04 November 2019

References

1. Fletcher CDM, World Health Organization, International Agency for Research on Cancer. WHO classification of tumours of soft tissue and bone. 4th ed. Lyon: IARC Press; 2013. p. 468.

2. Bray F, Ferlay J, Soerjomataram I, Siegel RL, Torre LA, Jemal A. Global cancer statistics 2018: GLOBOCAN estimates of incidence and mortality worldwide for 36 cancers in 185 countries. CA Cancer J Clin. 2018;68(6):394-424 PubMed PMID: 30207593.

3. Brennan MF, Antonescu CR, Moraco N, Singer S. Lessons learned from the study of 10,000 patients with soft tissue sarcoma. Ann Surg. 2014;260(3): 416-21 discussion 21-2. PubMed PMID: 25115417. Pubmed Central PMCID: 4170654.

4. Wibmer C, Leithner A, Zielonke N, Sperl M, Windhager R. Increasing incidence rates of soft tissue sarcomas? A population-based epidemiologic study and literature review. Ann Oncol. 2010;21(5):1106-11 PubMed PMID: 19858086.

5. Clark MA, Fisher C, Judson I, Thomas JM. Soft-tissue sarcomas in adults. N Engl J Med. 2005;353(7):701-11 PubMed PMID: 16107623.

6. Lewis JJ, Leung D, Woodruff JM, Brennan MF. Retroperitoneal soft-tissue sarcoma: analysis of 500 patients treated and followed at a single institution. Ann Surg. 1998;228(3):355-65 PubMed PMID: 9742918. Pubmed Central PMCID: 1191491.

7. Bonvalot S, Rivoire M, Castaing M, Stoeckle E, Le Cesne A, Blay JY, et al. Primary retroperitoneal sarcomas: a multivariate analysis of surgical factors associated with local control. J Clin Oncol. 2009;27(1):31-7 PubMed PMID: 19047280.

8. Nussbaum DP, Rushing CN, Lane WO, Cardona DM, Kirsch DG, Peterson BL, et al. Preoperative or postoperative radiotherapy versus surgery alone for 
retroperitoneal sarcoma: a case-control, propensity score-matched analysis of a nationwide clinical oncology database. Lancet Oncol. 2016;17(7):966-75 PubMed PMID: 27210906.

9. Gronchi A, Lo Vullo S, Fiore M, Mussi C, Stacchiotti S, Collini P, et al. Aggressive surgical policies in a retrospectively reviewed single-institution case series of retroperitoneal soft tissue sarcoma patients. J Clin Oncol. 2009;27(1):24-30 PubMed PMID: 19047283.

10. Trans-Atlantic RPSWG. Management of primary retroperitoneal sarcoma (RPS) in the adult: a consensus approach from the Trans-Atlantic RPS Working group. Ann Surg Oncol. 2015;22(1):256-63 PubMed PMID: 25316486.

11. Bagaria SP, Neville M, Gray RJ, Gabriel E, Ashman JB, Attia S, et al. The volume-outcome relationship in retroperitoneal soft tissue sarcoma: evidence of improved short- and long-term outcomes at high-volume institutions. Sarcoma. 2018;2018:3056562 PubMed PMID: 30140165. Pubmed Central PMCID: 6081523

12. Berger NG, Silva JP, Mogal H, Clarke CN, Bedi M, Charlson J, et al. Overall survival after resection of retroperitoneal sarcoma at academic cancer centers versus community cancer centers: an analysis of the national cancer data base. Surgery. 2018;163(2):318-23 PubMed PMID: 28943041.

13. Keung EZ, Chiang YJ, Cormier JN, Torres KE, Hunt KK, Feig BW, et al. Treatment at low-volume hospitals is associated with reduced short-term and long-term outcomes for patients with retroperitoneal sarcoma. Cancer. 2018;124(23): 4495-503 PubMed PMID: 30317543. Pubmed Central PMCID: 6289614.

14. Gustafson P, Dreinhofer KE, Rydholm A. Soft tissue sarcoma should be treated at a tumor center. A comparison of quality of surgery in 375 patients. Acta Orthop Scand. 1994;65(1):47-50 PubMed PMID: 8154283.

15. Bhangu AA, Beard JA, Grimer RJ. Should soft tissue sarcomas be treated at a specialist centre? Sarcoma. 2004:8(1):1-6 PubMed PMID: 18521386. Pubmed Central PMCID: 2395603

16. Speicher PJ, Englum BR, Ganapathi AM, Wang X, Hartwig MG, D'Amico TA, et al. Traveling to a high-volume center is associated with improved survival for patients with esophageal cancer. Ann Surg. 2017;265(4):743-9 PubMed PMID: 28266965. Pubmed Central PMCID: 5143210

17. Lidsky ME, Sun Z, Nussbaum DP, Adam MA, Speicher PJ, Blazer DG 3rd. Going the extra mile: improved survival for pancreatic cancer patients traveling to high-volume centers. Ann Surg. 2017;266(2):333-8 PubMed PMID: 27429020

18. Lerro CC, Robbins AS, Phillips JL, Stewart AK. Comparison of cases captured in the national cancer data base with those in population-based central cancer registries. Ann Surg Oncol. 2013;20(6):1759-65 PubMed PMID: 23475400.

19. Robusto CC. The cosine-Haversine formula. Am Math Mon. 1957;64(1):38-40.

20. Schneider EB, Ejaz A, Spolverato G, Hirose K, Makary MA, Wolfgang CL, et al. Hospital volume and patient outcomes in hepato-pancreatico-biliary surgery: is assessing differences in mortality enough? J Gastrointest Surg. 2014;18(12):2105-15 PubMed PMID: 25297443.

21. Chioreso C, Del Vecchio N, Schweizer ML, Schlichting J, Gribovskaja-Rupp I, Charlton ME. Association between hospital and surgeon volume and recta cancer surgery outcomes in patients with rectal cancer treated since 2000: systematic literature review and meta-analysis. Dis Colon Rectum. 2018; 61(11):1320-32 PubMed PMID: 30286023.

22. Begg CB, Cramer LD, Hoskins WJ, Brennan MF. Impact of hospital volume on operative mortality for major cancer surgery. JAMA. 1998;280(20):174751 PubMed PMID: 9842949.

23. Falcoz PE, Puyraveau M, Rivera C, Bernard A, Massard G, Mauny F, et al. The impact of hospital and surgeon volume on the 30-day mortality of lung cancer surgery: a nation-based reappraisal. J Thorac Cardiovasc Surg. 2014; 148(3):841-8 discussion 8. PubMed PMID: 24534677.

24. Birkmeyer JD, Siewers AE, Finlayson EV, Stukel TA, Lucas FL, Batista I, et al. Hospital volume and surgical mortality in the United States. N Engl J Med. 2002;346(15):1128-37 PubMed PMID: 11948273.

25. Finks JF, Osborne NH, Birkmeyer JD. Trends in hospital volume and operative mortality for high-risk surgery. N Engl J Med. 2011;364(22):212837 PubMed PMID: 21631325. Pubmed Central PMCID: 3150488.

26. Reames BN, Ghaferi AA, Birkmeyer JD, Dimick JB. Hospital volume and operative mortality in the modern era. Ann Surg. 2014;260(2):244-51 PubMed PMID: 24368634. Pubmed Central PMCID: 4069246

27. Maurice MJ, Yih JM, Ammori JB, Abouassaly R. Predictors of surgical quality for retroperitoneal sarcoma: volume matters. J Surg Oncol. 2017;116(6):76674 PubMed PMID: 28608360
28. Adam MA, Moris D, Behrens S, Nussbaum DP, Jawitz O, Turner M, et al. Hospital volume threshold for the treatment of retroperitoneal sarcoma. Anticancer Res. 2019;39(4):2007-14 PubMed PMID: 30952744.

29. Blay JY, Honore C, Stoeckle E, Meeus P, Jafari M, Gouin F, et al. Surgery in reference centers improves survival of sarcoma patients: a nationwide study. Ann Oncol. 2019;30(7):1143-53 PubMed PMID: 31081028. Pubmed Central PMCID: 6637376.

30. Finlayson SR, Birkmeyer JD, Tosteson AN, Nease RF Jr. Patient preferences for location of care: implications for regionalization. Med Care. 1999;37(2): 204-9 PubMed PMID: 10024124.

31. Lin CC, Bruinooge SS, Kirkwood MK, Olsen C, Jemal A, Bajorin D, et al. Association between geographic access to cancer care, insurance, and receipt of chemotherapy: geographic distribution of oncologists and travel distance. J Clin Oncol. 2015;33(28):3177-85 PubMed PMID: 26304878. Pubmed Central PMCID: 4979096.

\section{Publisher's Note}

Springer Nature remains neutral with regard to jurisdictional claims in published maps and institutional affiliations.

Ready to submit your research? Choose BMC and benefit from:

- fast, convenient online submission

- thorough peer review by experienced researchers in your field

- rapid publication on acceptance

- support for research data, including large and complex data types

- gold Open Access which fosters wider collaboration and increased citations

- maximum visibility for your research: over $100 \mathrm{M}$ website views per year

At BMC, research is always in progress.

Learn more biomedcentral.com/submissions 